\title{
Research on Chinese Consumer Behavior and Optimization of E-commerce Platform Marketing in the Context of Post Epidemic Situation
}

\author{
Hao Wang ${ }^{1, *},{ }^{*}$, Haichen Yin ${ }^{2, \dagger}$ \\ ${ }^{1}$ School of Accounting, Central University of Finance and Economics, Beijing, 100081, China \\ ${ }^{2}$ Business School, Yangzhou University, Jiangsu,212000, China \\ *Corresponding author. Email: guanghua.ren@gecacdemy.cn \\ These authors contributed equally.
}

\begin{abstract}
With the continuous development of the Internet economy, people are not satisfied with traditional online shopping. Fresh community group shopping came into being. The outbreak in 2020 made people aware of the potential of community group buying. Internet companies keenly seize this opportunity and join the competition to seize market share. With the vigorous development of fresh community group buying, its marketing strategy has exposed many problems, which will affect the long-term development of community fresh group buying. Taking Duoduo to buy vegetables as an example, this paper analyzes fresh community group buying development status and marketing promotion strategy. Through the research, it is found that there are deficiencies in the price strategy, commodity strategy, and channel strategy in the marketing promotion strategy of buying more vegetables. Based on this, based on the new $4 \mathrm{C}$ theory, this paper puts forward optimization suggestions for the marketing promotion strategy of buying more vegetables from the three dimensions of content, connection, and scene.
\end{abstract}

Keywords: Post epidemic situation, E-commerce platform, Consumer behavior characteristics, countermeasure.

\section{INTRODUCTION}

The body text starts with a standard first-level heading like INTRODUCTION or any other heading suitable to the content and context. First-level headings are in all caps. Copy the content and replace it with other first-level headings in the remaining text. Reference citations should be within square brackets [1]. Headings should always be followed by text.

The world has been upside down since the outbreak of covid-19, and all trades and professions are facing tremendous changes.

From the performance of the TOP 10 countries of the global online retail, China has been the world's top place for eight consecutive years. In 2020, the market size will be 2.3 trillion US dollars, with an annual growth rate of $27.5 \%$. In 2021, it will still maintain a high growth rate of $21 \%$, and it will be the first country where online consumption exceeds physical retail [1].

In the post epidemic era, a "new retail" business model has emerged in China, that is, relying on the Internet, enterprises use big data, artificial intelligence, and other advanced technology means to upgrade the production, circulation, and sales process of goods, thus reshaping the business structure and ecosystem, and deeply integrating online service, offline experience and modern logistics [2]. There are two reasons for its appearance: the structural change of consumption relationship and the development of digitalization.

Due to the epidemic's impact, consumers mainly focus on online activities, and consumer behavior accelerates online. According to the e-market's prediction, China's online retail will maintain a high growth rate of $21 \%$ in 2021 and become the first country where online consumption exceeds physical 
retail [1]. Additionally, the communication between brands and consumers is more direct, and the decentralized development reduces the demand for traditional intermediaries. E-commerce has also broken through the distance between time and space, creating new growth points for traditional consumption. In the new round of consumer relations, the brand side takes the consumer value as the core, creates products more in line with the needs of consumers, and promotes the diversified and personalized development of products.

In addition, digital penetration of the development of e-commerce. Cloud computing and big data promote the integration of online, offline, and multi-business. The digitalization of the supply chain makes the process of production, storage, and logistics synchronized in real time and the management more accurate. Consumer experience digitization provides personalized recommendations by collecting browsing records and purchase records of consumers to further tap the potential of consumers.

As the main part of "new retail", the e-commerce industry is of great value in the market research in the post epidemic era. The fresh food business of ecommerce develops rapidly under the situation of home isolation of epidemic situation. Pinduoduo launched "Duoduo buy vegetables" and put it on the most prominent home page, becoming a strong opponent in the fresh brand.

At present, some scholars have studied the marketing promotion strategy of fresh community group buying, and most of them focus on the field of logistics distribution optimization. Liu focused on community group buying in b-end e-commerce and explored the practical operation ideas of community group buying warehouse distribution mode [3]. Liu aimed at the shortcomings of the existing research on community group buying pricing and vehicle routing problems, helped community group buying enterprises to better formulate the price and cold chain distribution path planning [4]. Under the background of the "Internet +" era, Chen discussed the current situation and problems of community group buying and analyzed the development trend of community group buying promoted by smart logistics [5]. Part of the research focused on the research of consumers' and leaders' willingness. Yin explored the impact of perceived usefulness, perceived ease of use, perceived pleasure, personal innovation, word-of-mouth, subjective norms, and trust on consumers' willingness to use community group buying, and put forward corresponding suggestions on the management of fresh community group buying enterprises [6]. Pan studied the optimization of the end distribution of fresh electricity suppliers through several e-commerce platforms [7]. Ni and Zheng studied several fresh produce electronic businesses' expense ratios, specifically logistics, manpower, and advertising [8]. Peng focused on healthy [8]. Most scholars have studied the supply chain and management in the fresh produce electronic business. However, few researchers have mentioned the application of New 4Cs theories in fresh produce electronic business.

This paper will take Duoduo to buy vegetables as an example, adopt the research methods of literature analysis and questionnaire survey, use the new 4C theory, and on this basis, put forward the corresponding suggestions on how to promote the marketing of fresh produce electronic business.

\section{METHOD}

\subsection{Literature research method}

The literature research method mainly refers to the collection, identification, collation of literature and through the study of literature to form a scientific understanding of the facts [6].

The classification of this literature comes from the core journal papers, professional industry report data, and the latest new 4C theory. Based on the comprehensive collection of literature on "community group buying in the post epidemic era", this paper summarizes, analyzes, and identifies the literature. It systematically and comprehensively describes and comments on the research results and progress of the economy under the epidemic situation and the ecommerce community group buying in the development stage in a certain period. We point out the current level, trends, problems to be solved. The future development direction of community group buying, puts forward its own views, opinions, and suggestions and reviews the research results of various community group buying ecommerce based on relevant theories, research conditions, and actual needs to provide a basis or conditions for the current research.

\subsection{Questionnaire survey method}

The questionnaire is a widely used method in the social survey at home and abroad. It is a method for researchers to use this controlled measurement to measure the research questions to collect reliable data [7].

In this paper, we specially make a questionnaire about "the use and development prospects of community group buying such as buying more vegetables in the current epidemic situation". Our opinion is mainly to issue questionnaires to consumers who have used fresh community group buying. We sort out and analyze consumers' experience of using fresh community group buying according to the collected data. On this basis, we roughly judge the development 
status of fresh community group buying, summarize the shortcomings of the current fresh group buying marketing promotion strategy, explore the causes, and provide ideas to solve this dilemma.

\subsection{Statistical analysis}

Statistical analysis method refers to a research method to understand and reveal the mutual relationship, change law and development trend of things through the analysis and research of the quantitative relationship of the scale, speed, scope, and degree of the research object, to achieve the correct interpretation and prediction of things [8].

This paper summarizes, analyzes, and classifies the questionnaire survey results and uses the data to make a variety of histograms such as "the distribution map of consumers' main motivation to choose community group buying consumption". By analyzing the influencing factors, draw a "more fresh vegetables to buy community group buying model diagram". Through the analysis of charts and data, we can intuitively and accurately get the problems and advantages of community group buying e-commerce, the main factors that affect the problem of community group buying, and how to solve them.

\section{RESULT}

A total of 101 questionnaires were collected, covering students, enterprise employees, enterprise managers, self-employed, full-time at home, and other industries. All of them have an education level of technical secondary school or above, and $85 \%$ of them have a monthly income of 0-4000 yuan. We divide the analysis results into the following three aspects.

\subsection{Analysis of Chinese consumer behavior in the background of post epidemic situation}

\subsubsection{Analysis of survey results}

According to the survey results, consumers are more inclined to buy goods online during the epidemic period. Only $50 \%$ of the respondents have used the community group-buying platform, and the number of people who know about community group buying during the epidemic period has not changed substantially. Among the people who know about community group buying, there are platforms, community organizations, social media, relatives, and friends, and more than $60 \%$ of them use Meituan to buy, most of them are fruits and vegetables. Low price and convenience are the main driving forces for people to adopt community group buying. The number of people who used too much to buy vegetables only accounted for $10 \%$ of the respondents, and the prevalence was obviously insufficient.

\subsubsection{Cause analysis}

The main reason is that the consumption habits of consumers are difficult to change in a short time. Chinese people always have the habit of choosing food materials from their parents and children. Most of them buy food materials on the spot. It seems unsafe and not fresh in online shopping. In general, the stalls selling fresh food are very close to residential areas, and there is no need for online shopping. Therefore, fewer people use online shopping.

\subsection{Analysis of the current situation of China's e-commerce platform marketing strategy under the background of post epidemic situation}

\subsection{1. industry background}

Fresh e-commerce has led to explosive growth. Since the emergence of fresh e-commerce, it has developed rapidly and maintained an annual growth rate of more than $30 \%$. In 2018, the market scale of fresh ecommerce reached 125.39 billion yuan, with a year-onyear growth of $38.8 \%$. In 2019, the growth pace of fresh e-commerce will slow down, and the market will enter a cooling-off period after the high-speed growth. The market scale is about 162 billion yuan, and it is expected to continue to grow steadily in 2020, exceeding 200 billion yuan [9].

During the Spring Festival, the daily transaction volume of Youxian increased 3-4 times, new and old users swarmed in, and the unit price of customers increased by about 30 yuan to more than 120 yuan. On the supply side, the average daily supply of excellent and fresh vegetables has doubled from 500 tons to more than 1000 tons. According to Ding Dong's vegetable shopping, under the epidemic situation, Ding Dong's vegetable orders on New Year's Eve rose by more than $300 \%$ compared with last month. Shortly, the overall order will increase by $80 \%$, and the unit price of customers will increase by $70 \%$. More than 40, 000 new users are added every day, of which natural growth accounts for more than $70 \%$ and about $10 \%$ of the total number of users placing orders.

At present, the rapid development of fresh ecommerce coexists in many formats, among which the front warehouse mode continues to be hot, new retail, community group, and other new modes continue to enter the market. With the increase of racetrack players and the expansion of giant layout, the competition of fresh e-commerce industry continues to upgrade. At the same time, it also accelerates the reshuffle of the original industry pattern. Since the launch of multipoint in 2015 , relying on local large-scale supermarkets, it has 
carried out online and offline integrated scene operations with outstanding effect. In particular, Wumart supermarket launched the "free purchase" mobile phone self-checkout sales mode, which is very popular with users, and also brings multipoint to the leading position in the field of fresh e-commerce.

\subsubsection{Analysis of Duoduo's buying strategy}

\subsubsection{Commodity strategy}

Fresh products play a key role in attracting customers. Fresh food is a necessary part of three meals a day, and consumers have a strong demand. Generally

$60.00 \%$
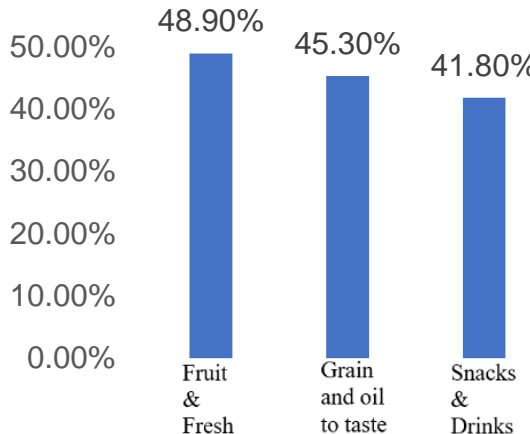

speaking, the significance of fresh food in the sinking market is higher than that in the head cities. The more sinking areas, such as some second- and third-tier cities, have a relatively high proportion of food consumption in the consumption structure of residents.

According to the data obtained from questionnaire question 15 , it can be seen that group-buying of fresh food and food accounts for the largest proportion of consumers, followed by grain and oil seasoning, followed by snacks and beverages, household products, washing and care products, maternal and child products and other commodities. The specific proportion is shown in Figure 1.

Figure 1 Investigation on group purchase categories of fresh food in the community.

\section{$\underline{\text { 3.2.2.2. Price strategy }}$}

Low price strategy: similar to 10 billion yuan subsidy, special cash subsidy and full discount coupons are provided for new users who buy more vegetables. Coupons will be returned after a successful purchase. Old users will issue coupons from time to time and reduce the threshold of package mail.

This paper selects Kunshan City, which is more mature in developing fresh community group buying, to compare the prices. The group-buying platform of the fresh community selects Duoduo (under pinduoduo) and Meituan Youyou (under Meituan), the fresh ecommerce selects daily Youxian and HEMA Xiansheng, and the local supermarket selects RT mart and WalMart to compare the prices of fresh products and standard products. According to the above statistical data, table 1 is obtained. As shown in Table 1, community group-buying is about $25-30 \%$ cheaper, and fresh e-commerce is about $20-25 \%$ more expensive. It can be seen that group-buying of fresh food in the community has obvious price advantages compared with supermarkets and fresh food e-commerce.

Table 1. Price proportion of community group buying and fresh e-commerce based on supermarkets.

\begin{tabular}{cccc}
\hline Categories & The & Fresh & Business \\
& communit & produce & super \\
& y group & $\begin{array}{c}\text { electronic } \\
\text { business }\end{array}$ & \\
& & cusion & \\
\hline
\end{tabular}

\begin{tabular}{cccc}
\hline $\begin{array}{c}\text { Fresh } \\
\text { produce- } \\
\text { melon and } \\
\text { fruit }\end{array}$ & $59 \%$ & $136 \%$ & $100 \%$ \\
$\begin{array}{c}\text { Fresh } \\
\text { produce- }\end{array}$ & $76 \%$ & $128 \%$ & $100 \%$ \\
$\begin{array}{c}\text { vegetables } \\
\text { Fresh } \\
\text { produce- } \\
\text { meat and } \\
\text { eggs }\end{array}$ & $83 \%$ & $124 \%$ & $100 \%$ \\
$\begin{array}{c}\text { Product- } \\
\text { food and } \\
\text { drink }\end{array}$ & $84 \%$ & $123 \%$ & $100 \%$ \\
Product- \\
daily & $78 \%$ & $121 \%$ & $100 \%$ \\
necessities & & & \\
\hline
\end{tabular}

\subsubsection{Channel strategy}

A marketing channel is a process that products reach consumers through the operation of manufacturers [10]. There are direct and indirect channel strategies for group buying enterprises in the fresh community. The direct channel strategy is to use advertisements to attract consumers to $\log$ in to the fresh community group purchase-related software or to serve the official account and place orders directly according to their needs. The indirect channel strategy is to attract consumers in the community to place orders through the call of the head of fresh community group buying. 


\subsection{Problems in the marketing strategy of China's e-commerce platform under the background of post epidemic situation}

\subsection{1.an insight into the overall industry}

Because of poor management, they continue to burn money. However, the profit level is far lower than the input cost, so few e-commerce companies can profit. According to the statistical data, in 2018, 4\% of the more than 4000 players in fresh e-commerce were flat, $88 \%$ were still in a loss state, $7 \%$ were in a huge loss, and only $1 \%$ realized a profit [11]. Figure 2 shows the proportion of profitability structure of China's fresh produce electronic business.

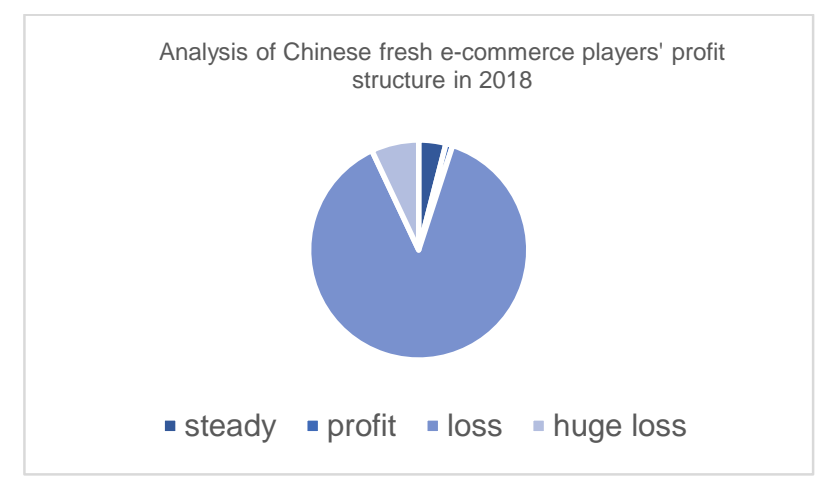

Figure 2 the proportion of profitability structure of China's fresh produce electronic business.

\subsubsection{Analysis of the problem of Duoduo shopping}

Community a is a residential community in Kunshan, with 8200 residents. Two fresh community group buying outlets (both are Duoduo shopping outlets), namely express station and grocery store. I distributed 101 questionnaires to the residents who completed consumption in the community group buying point, cancelled zero of them, and took back 101. Based on the above questionnaire data, the following questions are analyzed.

\subsubsection{The variety of commodities is single, and homogenization is serious}

According to the feedback data of questionnaire question 9, Figure 3 is made. From Figure 3, it can be seen that most consumers give a score of 1-3 to the richness of the group buying products in the fresh community, while a small number of consumers give a score of 4-5. Most customers think that the richness of group buying products in the fresh community is not enough. Although the product strategy of fresh community group-buying is "using fresh drainage, using standard products to make money". But in fact, the main commodities they provide and sell are fresh products and a small number of daily necessities. At present, what they do is only fresh drainage, and only a few consumers buy standard products. Therefore, the overall profit of group buying in fresh communities is not high. Combined with my experience in using fresh community group buying, the types of commodities provided by fresh community group buying are relatively single, and the homogenization is serious. This may be the result of the two-way choice between enterprises and consumers. Consumers usually choose fresh products and daily necessities and buy fewer other products. When enterprises get this feedback, they choose to take advantage of it, increase the supply of fresh and daily necessities and reduce the supply of other commodities. For a long time, the supply of fresh and daily necessities is too saturated and homogenized, while the supply of other commodities is in shortage, even out of the fresh community group purchase list. This result is obviously contrary to the original vision.

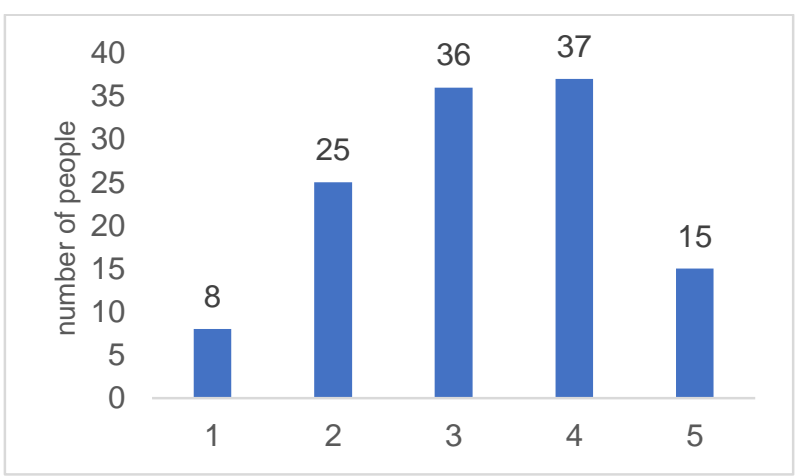

Figure 3 satisfaction survey of category richness

\subsubsection{Product quality is lack of guarantee, and after-sales service is chaotic}

Due to many factors such as improper storage, unfavorable personnel sorting, delayed delivery, the quality problems of fresh goods occur frequently. Because the production process of basic fresh and cooked food products is difficult to be standardized, food safety problems frequently occur, which reduces the trust and enthusiasm of consumers to a certain extent. The group-buying platform and team leader are mainly responsible for the after-sales of fresh community group buying. At the same time, most consumers choose to solve the problem nearby in the actual operation process. Figure 4 is obtained from the information integration of questionnaire question 9. As shown in Figure 4, the satisfaction image of after-sales evaluation is similar to the satisfaction image of the team leader's ability to a large extent. The satisfaction image of after-sales evaluation is positively correlated with the team leader's ability. That is to say, the consumer's after-sales satisfaction depends on the team leader's ability to a certain extent. Due to the lack of professional and special management of community 
group buying outlets, the doubts and problems of consumers cannot be answered in time. It will lead to the operation confusion of outlets and the disgust of consumers, and the after-sales satisfaction of consumers is naturally not high.

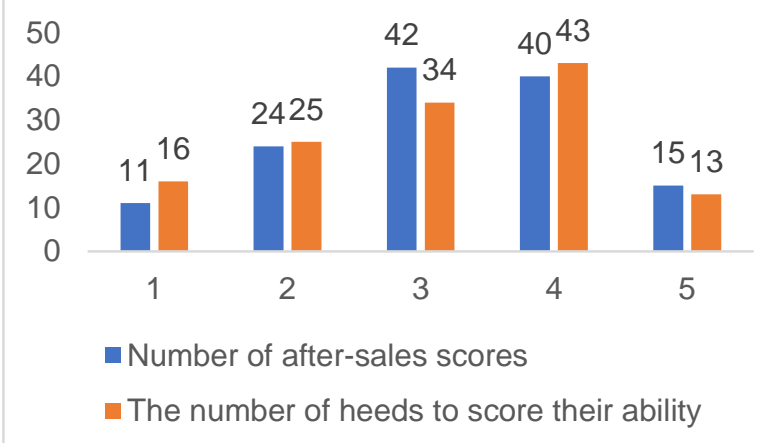

Figure 4 after-sales evaluation and satisfaction survey

\subsubsection{Online and offline separation, channel strategy is lack of pertinence}

In the actual operation, the indirect channel strategy is not effective. The appeal of the team leader is often limited. Most of the time, the team leader has little contact with consumers and only undertakes the role of distribution after the arrival of the final goods. The maintenance of the active Wechat group is out of the question. The lack of the "connection" role of the team leader leads to the complete separation of online and offline.

According to the survey of Kaidu data, the penetration rate of online shopping crowd in the firsttier cities was $73 \%$ in 2017, while that in the fourth and fifth-tier cities was less than $60 \%$ [10]. It indicates that the penetration rate of the online shopping crowd in the low-tier cities has more room to improve. The sinking market is the main source of potential online shopping users in the future. The more sinking users, the higher the proportion of their food expenses in their total expenses, which coincides with the content strategy of fresh community group buying. It can be seen that the focus of the fresh community group buying channel strategy is sinking market, and the goal is to quickly obtain the flow of sinking market users in a short time. However, there is no clear distinction between the firstline and low-line markets, and the long-term channel strategy lacks pertinence.

\section{DISCUSSION}

\subsection{Content: differentiated supply of goods, focusing on the development of the sinking market}

The fresh community group buying market in the first-tier cities is relatively mature, the consumer price sensitivity is low, and the demand for product richness is high. Therefore, it is necessary to appropriately reduce the supply proportion of fresh products and daily necessities in the first-tier city market. In some districts where the group buying operation of fresh communities is more successful, we can pilot the sale of high-value and easy-to-sell goods, such as digital products and customized services, to enrich the choice and stabilize the market. The construction of the community group buying market in offline cities is relatively imperfect. The consumer price sensitivity is high, the demand for product richness is not high, and the focus is on fresh products.

Therefore, it is necessary to increase the supply proportion of fresh products and daily necessities in aftermarket, subsidize these markets, lower prices, and seize market share.

\subsection{Connection: positioning key communication sources, uniting with government publicity, maintaining community stability}

The Ministry of Commerce issued the notice on the work of flood protection for living materials in the key city. The emphasis was placed on the equal emphasis on market principles and the government's compensation and protection. Epidemic prevention and control should be emphasized equally. Under the "COVID-19", the market consumption line gradually sank to the last mile or even the last one hundred meters with increasingly stringent public control measures. Consumers' dependence on community business services has increased significantly. Marketing should comply with government propaganda, respond to the call of national epidemic prevention, and publicize community group buying

Community group-buying focuses on interpersonal communication. Interpersonal communication is the transmission of information through contact between people, and each member of the community is a source of communication [12]. Information is constantly spread among different sources to achieve rapid fission. Therefore, if there is a service or product problem and it is not handled as soon as possible, it will have a fatal impact on the whole community. The sustainability of the community mainly depends on whether its members can trust each other and interact continuously. Therefore, the fresh community group buying enterprises need to locate the key communication source of the community. They are often activists and opinion leaders in the community. Let them become the team leader to carry out group buying, guide users' consumption, carry out after-sales on behalf of the enterprise, and guide the community public opinion. 


\subsection{Community: build a community with value identity, play the role of team leader, and split users}

The community is not a general group, but a special group based on the social relationship chain, with a basic point (common needs and hobbies) to gather people, and members have the ability to act in concert. Community group buying, social fission, take interpersonal relationship and neighborhood relationship as the leverage, enjoy the traffic dividend of community transportation, through the group and neighborhood relationship, we can quickly fission and obtain traffic. It greatly reduces the cost of acquiring customers.

From the marketing perspective, community groupbuying is based on the relationship between acquaintances and semi acquaintances of location-based services. The team leader pulls friends and neighbors into the group and turns them into traffic. Therefore, community group buying has the dual attributes of relationship marketing and word-of-mouth marketing. Community group-buying should maintain the relationship between group members based on product quality and topic, select high-quality products suitable for the community from the characteristics of community consumers, win consumers' trust through word of mouth, improve consumption viscosity, expand consumer groups and build brands.

The head of the group is responsible for the role of upload and release, which is an important part of community building. However, most of the heads do not have this kind of professional ability. Fresh community group buying enterprises need to strengthen the assessment of the head of the group and reward and punish them according to their performance. Those who fail to pass the long-term assessment will be dismissed, and those who perform well will be subsidized. While absorbing a large number of part-time team leaders, we should also cultivate a number of professional team leaders.

\subsection{Context: user portrait analysis, custom consumption scenario}

The background of the new 4C theory is the mobile Internet era, which is different from any traditional background. Different from the traditional theory, in the view of the new $4 \mathrm{C}$ theory, the scene is a synthesis of four elements: consumption demand, consumption time, place, and customer emotion. The scene plays an important role in the group buying economy as a place where content contacts users. Demand scenarios refer to the WeChat app, group buying apps, which gather consumers with similar purchase needs. The time scene includes the key shopping nodes, such as group buying, group members' group shopping, and network delivery; Location scene: Online app, offline stores, community outlets; Customer sentiment involves the feeling of consumers before placing an order, waiting for the goods to be received, and harvesting after consumption [13].

Scene theory divides the original complete shopping process into independent but interactive parts. It enables community group buying enterprises to start from many aspects simultaneously and create customized consumption scenes for consumers relying on artificial intelligence and big data technology. Compared with the first-tier cities, consumers in offline cities have low education levels, low timeliness sensitivity, scattered residence, and high price sensitivity. Therefore, it can simplify the group purchase app and WeChat applet. Reduce the priority of logistics timeliness appropriately. Take cost control as the core, reduce the cost as much as possible without affecting the quality of goods and services, and improve the bargaining power. The company adds fresh group-buying service outlets, step by step, to open up the rural market.

\section{CONCLUSION}

\subsection{Summary main findings}

This paper holds that fresh community group-buying is the product of the interaction between consumers, heads, and fresh community group buying enterprises. The research on fresh community group buying should not separate the above three. Still, it should take the head as the link connecting consumers and fresh groupbuying enterprises and study the network structure composed of the above three as a whole. With the help of the new 4C theory, we can build a new fresh community group purchase marketing promotion strategy of "differentiated content, customized scenes, integrated community, and stable connection". Fresh group-buying enterprises distinguish the first-line market from the offline market and provide differentiated goods to meet the needs of different consumers, focus on the development of sinking market and create customized consumption scenarios for its consumers, strengthen the assessment of leaders, improve their professional service ability, and let them play an important role in maintaining community stability and marketing information publicity within the community. In this way, fresh community group buying enterprises can get rid of the price war, turn to community incubation, win traffic through quality and reputation, and achieve long-term sustainable development.

\subsection{Limitation}

Our sample size is limited to 101 , so there may be a contingency to some degree. The larger the size of our sample size, the closer the result will be to reality. Also, 
the respondents are mainly students, while others scatter into managers, housewives, white-collar workers, etc. The frequency of using online approaches to buy fresh food largely depends on the age and work of the people. There's still a possibility to allocate the respondents more averagely to different groups. What's more, the number of people who have used e-commerce to buy fresh food is too small to give a convincing result, which produced much useless data.

\section{REFERENCES}

[1] eMarketer, Global E-commerce Report 2020-2021

[2] Du Ruiyun, Jiang Kan. New retail: connotation, development motivation and key issues. Price theory and practice, 2017 (02): 139-141

[3] Liu Tianyu. Research on Optimization of warehouse distribution mode of community group buying fresh third-party platform under time window constraints . Zhengzhou University, 2019

[4] Liu Qian. Collaborative optimization of community group purchase pricing and vehicle distribution path of fresh agricultural products. Kunming University of technology, 2020

[5] Chen Zhongyan. Current situation of community group purchase and development trend of community group purchase driven by smart logistics. Management and technology of small and medium-sized enterprises (last ten days), 2021 (04): 122-123

[6] Yin Yaoling. Study on Influencing Factors of consumers' community group purchase intention. Jilin University, 2020

[7] Pan Sihao, Gao Yajing, Lei Yinuo, Zhu Changning. Research on terminal distribution optimization of fresh e-commerce in the post epidemic era. National circulation economy, 2020 (34): 12-16

[8] Ni Xiang, Zheng Zheng. We sell fresh food in the post epidemic era. Business culture, 2020 (36): 3847

[9] Peng Xiaomei. Post epidemic era of China's food industry: fresh e-commerce health products usher in new opportunities. China food industry, 2020 (z1): 31-34

[10] Analysis on market status and development prospect of China's fresh e-commerce industry in 2020 https://www.sohu.com/a/379837187_ one hundred million eighty-six thousand two hundred and one

[11] Insight into the retail and e-commerce industries of Chinese foreign enterprises in the post epidemic era -- embracing the changing consumer experience, monstarlab

[12] Wei Yicong, Yu Runjia, Liu Keyu, Du Xinyi. Optimization and improvement of community group buying -- head rating and customer segmentation. National circulation economy, 2020 (22): $21-23$

[13] Zhang Wenbing, Yuan Huaiyu. Difficulties and Countermeasures of stimulating consumption in the post epidemic period. Modern commerce, 2021 (13): 9-11 